\title{
Electrochemical Nucleation:
}

\section{Comparison test of classical and atomistic nucleation models}

\author{
Juan Torrent-Burgués \\ Department of Chemical Engineering, Universitat Politècnica de Catalunya (UPC), \\ C/Colom 1, 08222 Terrassa (Barcelona), Spain.e-mail:juan.torrent@upc.edu
}

\begin{abstract}
Classical and atomistic nucleation models have been tested in several aqueous systems dealing with electrocrystallization. A lot of reported experimental nucleation data have been used, and in a wide range of overpotentials. The critical nucleus size has been calculated in those cases not reported in the original work, and the results obtained with the classical and atomistic models have been tabulated, compared and discussed. Small values for the critical nucleus size occur in most of the systems.
\end{abstract}

Keywords: electrochemical nucleation, classical model, atomistic model, critical nucleus size. 


\section{Introduction}

Theories of nucleation have been developed along the last decades, from both thermodynamic and kinetic points of view [1-7], since nucleation is an important phenomenon which plays a fundamental role in crystal growth, precipitation and electrocrystallization. The phenomenon of electrocrystallization has been treated by several authors [8-14] and also reviewed recently [15-19]. Nucleation and its control are very important in the formation of nanoparticles and nanostructured materials [20-25], and has also been applied to monolayers of molecular materials [26].

Dependence in between the nucleation rate and the overpotential acting in the system is predicted in the nucleation models. To test the classical models as well the atomistic model of nucleation, several systems have been selected dealing with electrochemical nucleation. One point that deserves attention in the discussions of the different nucleation models is that about the critical nucleus size. In this work this point has been considered and, from the treatment of experimental data, the critical nucleus size has been calculated for different systems, and some discussions are presented.

At first, immediately afterwards, a brief revision of the nucleation models is shown.

\section{Classical Models}

In the case of 3D homogeneous or heterogeneous nucleation, the following expressions are obtained for the critical nucleus $n *$, under the consideration that the surface of the nucleus is related to the power $2 / 3$ of the volume:

$$
\begin{gathered}
\Delta G\left(n^{*}\right)=\frac{b \omega^{2} \sigma^{3}}{(\Delta \mu)^{2}} F(\theta)=\frac{b \omega^{2} \sigma^{3}}{(k T \ln \beta)^{2}} F(\theta) \\
n^{*}=\frac{2 \Delta G\left(n^{*}\right)}{k T \ln \beta} F(\theta)
\end{gathered}
$$


where $b$ : shape factor, $\omega$ : molecular volume and $\beta$ : supersaturation ratio. The classical models use macroscopic magnitudes, as the interfacial tension $\sigma$, and the nucleus size is treated as a continuous value. The function $F(\theta)$ takes the value of 1 for homogeneous nucleation and depends on the contact angle, or the adhesion energy, between substrate and nucleation phase in the case of heterogeneous nucleation. This function is usually neglected in practise. A proposed solution [16] is to consider $\sigma$ as an average specific interface energy that takes into account for the interface energy between nucleus and substrate. Under this assumption, the above expressions can be rewritten as:

$$
\begin{gathered}
\Delta G\left(n^{*}\right)=\frac{k T B_{3 D}}{(\ln \beta)^{2}} \\
n^{*}=\frac{2 B_{3 D}}{(\ln \beta)^{3}} \\
B_{3 D}=\frac{b \omega^{2} \sigma^{3}}{(k T)^{3}}
\end{gathered}
$$

The kinetic approach to the nucleation process considers that the nucleus formation proceeds in a reversible process by addition and aggregation of individual particles, where some aggregates growth while others redissolve, and some of them reach the critical size. The nucleation rate takes the form:

$$
\begin{gathered}
J=Z c^{*} b^{*} \\
c^{*}=N_{1} \exp \left(-\frac{\Delta G^{*}}{k T}\right)
\end{gathered}
$$

In eq. (3a) $Z$ is the Zeldovich factor, $b^{*}$ is the probability of a monomer to be incorporated in the critical nucleus, and $c^{*}$ is the equilibrium concentration of the critical nuclei, expressed by eq. (3b) where $N_{1}$ is the monomer concentration. For most of the systems, the nucleation rate can be expressed by a general equation [5]: 


$$
J=J_{o} \exp \left(-\frac{\Delta G^{*}}{k T}\right)=J_{o} \exp \left(-\frac{B_{3 D}}{(\ln \beta)^{2}}\right)
$$

In eq. (4a) $J_{0}$ is a practically supersaturation independent term. Then

$$
B_{3 D} \approx-\frac{d \ln J}{d\left(\frac{1}{(\ln \beta)^{2}}\right)}
$$

Consequently, from eq. (4b) and (2b) the value of $n^{*}$ can be calculated.

For ionic solutions, if $\beta=S^{v}$, where $v^{\prime} v_{+}+v_{-}$and $v_{+}$and $v_{-}$represents the number of cations and anions in the molecular formula, respectively, the previous equations can be rewritten as:

$$
\begin{gathered}
J=J_{o} \exp \left(-\frac{B_{3 D}^{\prime}}{(\ln S)^{2}}\right) \\
B_{3 D}^{\prime}=\frac{B_{3 D}}{v^{2}} \approx-\frac{d \ln J}{d\left(\frac{1}{(\ln S)^{2}}\right)} \\
n^{*}=\frac{2 B_{3 D}^{\prime}}{v(\ln S)^{3}}
\end{gathered}
$$

\section{Atomistic Model}

In the atomistic model the critical nucleus size has a discrete character and is not a continuous function of supersaturation. Then, there is a supersaturation interval where the size of the critical nucleus is the same. For the nucleation rate we have the following expressions:

$$
\begin{gathered}
J=J_{o} \exp \left(-\frac{\Phi\left(n^{*}\right)-n^{*} \Delta \mu}{k T}\right) \\
\Phi\left(n^{*}\right)-n^{*} \Delta \mu=\Delta G\left(n^{*}\right)
\end{gathered}
$$


In the atomistic model $\Phi\left(n^{*}\right)$, the excess surface energy, and $n^{*}$ are constants in a given supersaturation interval and then $\ln J$ depends linearly on $\Delta \mu$ for each interval [6, 27], showing discontinuities when passing from one interval to another. Considering $J_{\mathrm{o}}$ as a practically supersaturation independent term, we have for each interval:

$$
\begin{aligned}
& n^{*}=\frac{d \ln J}{d \ln \beta} \\
& m^{*}=\frac{d \ln J}{d \ln S}
\end{aligned}
$$

When we deal with electrocrystallization, as $\ln \beta=z F \eta / R T$, where $\eta$ is the overpotential, we can write $[1,9,17,27]$ :

$$
n^{*}=\frac{R T d \ln J}{z F d \eta}
$$

\section{Results and discussion}

As can be seen from eq. (4a) and eq. (6a), nucleation models predict certain dependence between the nucleation rate and supersaturation, but one of the serious problems concerned with nucleation theories is their experimental test. In most of the works the nucleation rate $J$ is obtained. In those systems where the number of nuclei $N$ were reported for an instantaneous nucleation, it was assumed that $J \propto N[1,17]$ and then similar equations to eqs. (7a-7c) were used. In some cases the nucleation rate can be related to the induction time $t_{\mathrm{i}}$. The induction time includes the time for nucleation, $t_{\mathrm{n}}$, and the time for nucleus growth until a detectable size, $t_{\mathrm{g}}$. When exits a nucleation control $t_{\mathrm{n}}>>t_{\mathrm{g}}$, and then

$$
t_{i} \approx t_{n} \propto \frac{1}{J}
$$


For a simplicity in the data treatment, it will be assumed that this consideration holds and then, in eqs. (4b), (5b), (7a-7c), the term $d \ln J$ can be substituted by (-d $\ln t_{\mathrm{i}}$ ):

$$
\begin{gathered}
n^{*}=-\frac{d \ln t_{i}}{d \ln \beta} \\
m^{*}=-\frac{d \ln t_{i}}{d \ln S} \\
n^{*}=-\frac{R T d \ln t_{i}}{z F d \eta}
\end{gathered}
$$

In most systems, $T=298 \mathrm{~K}$ and thus $R T / F=0.0257 \mathrm{~V}$. For the atomistic model, plots of $\ln J$ or $\ln N$ or $\ln t_{\mathrm{i}}$ versus $\ln \beta$ or $\ln S$ or versus the overpotential $\eta$ were done, and from the slope and the corresponding equations the value of $n^{*}$ was determined. For the classical model, plots of $\ln J$ or $\ln N$ or $\ln t_{\mathrm{i}}$ versus $1 / \ln ^{2} \beta$ or $1 / \ln ^{2} S$ were treated, and from the slope and the corresponding equations the value of $n^{*}$ was determined. These models have been tested from experimental systems (Table 1 and Table 2). Table 1 shows the results of both the classical and the atomistic model, meanwhile Table 2 shows the results obtained only with the atomistic model. Some of the reported values have been calculated by the author from original data, but others were yet reported in the original paper.

The values of the critical nucleus size obtained with both classical and atomistic models agree (Table 1) and indicate that a small or very small critical nucleus is formed. This agreement is not strange since from eq. (4b) and eq. (2b) of the classical model it is obtained that $n^{*}=\mathrm{d} \ln J / \mathrm{d} \ln \beta$, which coincides with eq. (7a) of the atomistic model. Small values of the critical nucleus were also compiled by Krumm et al. (see Table 1 in ref [37]), with values ranging from 0 to 18, and by Budevski et al. (see Table 4.1 in ref [16]), with values ranging from 0 to 14 , for other systems in electrodeposition. The small values of $n^{*}$ obtained in electrocrystallization are due to the higher supersaturations usually attained in this case and 
to the heterogeneous character introduced by the electrode surface, with the presence of defects. These small values seem to reinforce that the atomistic model is more realistic.

Critical nucleus sizes of zero, which appears in some electrocrystallization systems at high overpotentials, can be explained by the presence of active sites on the electrode surface. The active sites play the role of the critical nucleus [10], and when the necessary overpotential or supersaturation is reached, nucleation occurs at these centres. Nanoscopic structural defects, ions, impurity molecules and foreign nanoparticles in the volume of the old phase or on the substrate surface are examples of such active centres [1]. The data in Table 2 clearly show that the higher values for the critical nucleus size occur at single crystals or at well defined crystalline faces, and at low enough overpotentials (systems E, F, K, R, S, U, V and b in Table 2), as a consequence of a lower density of defects in the substrate.

From the plot of $\ln J$ or $\ln t_{\mathrm{i}}$ vs. $\ln \beta$ or $\eta$ it is seen, in several systems, a change in the slope (systems A and E in Table 1 and systems F, L, P and R in Table 2) that according to the atomistic model indicates a change in the critical nucleus size, but in a discrete way. The existence of nucleus sizes more stable than others is predicted by the atomistic models $[2,6]$. Taken into consideration the very small determined critical nucleus size, it seems that magnitudes used by the classical models, as the interfacial tension, are without sense or meaning. But, on the other hand, the sizes predicted by the classical models agree with those of the atomistic model. This result seems to justify the formal use of classical models but the meaning of the magnitudes they use should be revised. Recently, Mostany et al. [60] have considered this point and proposed the temperature dependence of the nucleation rate, the interfacial tension and the exchange current densities as a way to analyse it. Small values of $n^{*}$ were also obtained by the author [61] in the precipitation of calcium carbonate from supersaturated solutions. It was also observed a linear dependence in the plot of $\ln t_{\mathrm{i}} \mathrm{vs}$. $\ln S$ with a change in the slope at a certain value of supersaturation, indicating a change in the value of $n^{*}$, as has been reported here for some systems in electrocrystalization. 
From considerations of the atomistic model $[8,17]$, when the critical nucleus size change $\Delta G\left(n_{1}{ }^{*}\right)=\Delta G\left(n_{2}{ }^{*}\right)$, and according to eq. (6b), it is possible to calculate $\Phi\left(n_{1}{ }^{*}\right)-\Phi\left(n_{2}{ }^{*}\right)$. Particularly, when $n^{*}$ change from 1 to 0 , the values of $\Phi(1)$ and $\Delta G(1)$ can be obtained. From the systems and values reported in Table 1 and Table 2, the results shown in Table 3 arise. The obtained values of $\Phi(1)$ indicate a certain correlation with the overpotential, being necessary higher overpotentials when the excess surface energy increases. Lower values of $\Phi(1)$ indicate a strong interaction with the substrate, as is the case of electrocrystalization of $\mathrm{PbSO}_{4}$ on $\mathrm{Hg} / \mathrm{Pb}$ amalgam (system $\mathrm{G}$ in Table 3). Due to the connection between the excess surface energy, of the atomistic model, and the interfacial tension, of the classical models, this low value can by related to a low value of the interfacial tension for this system.

Some studies on nucleation and growth at the initial stages of metal electrodeposition and nanoparticle formation have used Scanning Probe Microscopy (SPM) techniques, as STM and ECSTM [30, 52, 62-65] or AFM [39, 48, 66-67]. These nanometric techniques yield information on an atomic scale and provide a view of the electrodeposition process in a nanometric scale. Aspects such as the spatial distribution of nuclei, 2D or 3D dimensional growth, influence of defects and influence of additives or surface-capping agents, can be undertaken now in a more precise way. In particular, the number of nuclei, or the nucleation rate, as a function of the overpotential can be obtained more precisely with recent fast SPM than using other microscopy techniques as Scanning Electron Microscopy (SEM) [44, 46, 56, 68]. Furthermore, some of these techniques can be applied in-situ. A revision of the impact of these techniques on the analysis of electrochemical nucleation is out of the target of the present work. 


\section{Conclusions}

It can be concluded that the atomistic model can be applied to the electrochemical nucleation phenomenon, and that small values for the critical nucleus size are obtained. These small values are due to the high attained supersaturations and also to the presence of defects in the electrode surface. The presence of intervals where $\ln J$ depends linearly on $\Delta \mu$, according to the atomistic model, has been observed in several systems. 


\section{References}

1. Kashchiev D (2000) Nucleation. Basic Theory with Applications. ButterworthHeinemann, Oxford

2. Lewis B (1980) Nucleation and growth theory. In Pamplin BR (ed), Crystal Growth. Pergamon Press, Oxford, pp 23-63

3. Markov IV (1995) Crystal Growth for Beginners. World Scientific, Singapore

4. Jakubczyk M, Sangwal K (1994) Nucleation and precipitation processes. In Sangwal K (ed) Elementary Crystal Growth. Saan Publishers, Lublin, pp 43-82

5. Söhnel O, Garside J (1992) Precipitation. Butterworth-Heinemann, Oxford

6. Stoyanov S (1979) Nucleation theory for high and low supersaturations, In Kaldis E (ed)

Current Topics in Materials Science, vol 3. North-Holland Publishing Company, Amsterdam, pp 423-461

7. Toschev S (1973) Homogeneous nucleation. In Hartman P (ed) Crystal Growth: An Introduction. North-Holland Publishing Company, Amsterdam, pp 1-49

8. Milchev A (1991) Contemporary Physics 32:321-332

9. Milchev A, Stoyanov S (1976) J Electroanal Chem 72:33-43

10. Milchev A, Stoyanov S, Kaischew R (1974) Thin Solid Films 22:255-265

11. Bosco E, Rangarajan SK (1982) J Electroanal Chem 134:213-224

12. Gunawardena G, Hills G, Montenegro I, Scharifker B (1982) J Electroanal Chem $138: 225-239$

13. Milchev A, Lacmann R (1991) J Cryst Growth 110:919-924

14. Milchev A, Montenegro I (1992) J Electroanal Chem 333:93-102

15. Budevski E, Staikov G, Lorenz WJ (2000) Electrochim Acta 45:2559-2574

16. Budevski E, Staikov G, Lorenz WJ (1996) Electrochemical Phase Formation and Growth. VCH, Weinheim 
17. Milchev A (2002) Electrocrystallization. Fundamentals of Nucleation and Growth. Kluwer Academic Publishers, Boston

18. Milchev A (2011) J Solid State Electrochem 15:1401-1415

19. Milchev A (2008) Russ J Electrochem 44:619-645

20. Auer S, Frenkel D (2001) Nature 413:711-713

21. Klabunde KJ (2001) Nanoscale Materials in Chemistry. Wiley Interscience, NY

22. Liu H, Favier F, Ng K, Zach MP, Penner RM (2001) Electrochim Acta 47:671-677

23. Pileni MP (1998) Cryst Res Technol 33:1155-1186

24. Rodríguez-Clemente R, López A, Gómez J, Torrent-Burgués J, Castaño VM (1998) J European Ceramic Soc 18:1351-1356

25. Torrent-Burgués J, Rodríguez-Clemente R (2001) Crys Res Tech 36:1075-1082

26. Vollhardt D (2006) Adv Colloid Interf Sci 123-126:173-188

27. Kashchiev D (1982) J Chem Phys 76:5098-5102

28. Milchev A, Vassileva E (1980) J Electroanal Chem 107:337-352

29. Toschev S, Markov I (1967) Electrochim Acta 12:281-286

30. Hölzle MH, Zwing V, Kolb DM (1995) Electrochim Acta 40:1237-1247

31. Torrent J, Rodríguez R, Sluyters JH (1993) J Crystal Growth 131:115-123

32. Marquez K, Staikov G, Schultze JW (2003) Electrochim Acta 48:875-882

33. Milchev A, Heerman L (2003) Electrochim Acta 48:2903-2913

34. Dirkse TP (1990) Electrochim Acta 35:1445-1449

35. Yang M, Hu Z (2005) J Electroanal Chem 583:46-55

36. Bostanov V, Mladenova E, Kashchiev D (2000) J Electroanal Chem 481:7-12

37. Krumm R, Guel B, Schmitz C, Staikov G (2000) Electrochim Acta 45:3255-3262

38. Hyde ME, Klymenko OV, Compton RG (2002) J Electroanal Chem 534:13-17

39. Correia AN, Machado SAS, Avaca LA (2000) J Electroanal Chem 488:110-116

40. Soto AB, Arce EM, Palomar-Pardavé M, González I (1996) Electrochim Acta 41:2647- 
41. Oskam G, Vereecken PM, Searson PC (1999) J Electrochem Soc 146:1436-1441

42. Michailova E, Vitanova I, Stoychev D, Milchev A (1993) Electrochim Acta 38:2455-2458

43. Rigano PM, Mayer C, Chierchie T (1988) J Electroanal Chem 248:219-228

44. Scherb G, Kolb DM (1995) J Electroanal Chem 398:151-159

45. Vereecken PM, Strubbe K, Gomes WP (1997) J Electroanal Chem 433:19-31

46. Vazquez-Arenas J, Vázquez G, Meléndez AM, González I (2007) J Electrochem Soc 154:D473-D481

47. Milchev A, Zapryanova T (2006) Electrochim Acta 51:2926-2933

48. Ji C, Oskam G, Searson PC (2001) Surf Sci 492:115-124

49. Toschev S, Markov IV (1969) Ber Bunsenges Phys Chem 73:184-188

50. Milchev A, Tsakova V (1985) Electrochim Acta 30:133-142

51. Bort H, Jüttner K, Lorenz WJ, Staikov G, Budevski E (1983) Electrochim Acta 28:985991

52. Rashkova B, Guel B, Pötzschke RT, Staikov G, Lorenz WJ (1998) Electrochim Acta 43:3021-3028

53. Kelaidopoulou A, Kokkinidis G, Milchev A (1998) J Electroanal Chem 444:195-201

54. Milchev A, Stoychev D, Lazarov V, Papoutsis A, Kokkinidis G (2001) J Crystal Growth 226:138-147

55. Arbib M, Zhang B, Lazarov V, Stoychev D, Milchev A, Buess-Herman C (2001) J Electroanal Chem 510:67-77

56. Brylev O, Roué L, Bélanger D (2005) J Electroanal Chem 581:22-30

57. Guaus E, Torrent-Burgues J (2001) Portug Electrochim Acta 19:247-261

58. Sonneveld PJ, Visscher W, Barendrecht E (1992) Electrochim Acta 37:1199-1205

59. Alvarez AE, Salinas DR (2004) J Electroanal Chem 566:393-400

60. Mostany J, Scharifker BR, Saavedra K, Borrás C (2008) Russ J Electrochem 44:652-658

61. Gomez-Morales J, Torrent-Burgués J, Rodríguez-Clemente R (1996) J Cryst Growth 169:331-338 
62. Kolb DM (2002) The initial stages of metal deposition as viewed by Scanning Tunneling Microscopy. In Alkire RC, Kolb DM (ed) Adv in Electrochem Sci \& Engin, vol. 7. Wiley-VCH, Weinheim, pp 107-150

63. Gloaguen F, Léger JM, Lamy C, Marmann A, Stimming U, Vogel R (1999) Electrochim Acta 44:1805-1816

64. Kibler LA, Kleinert M, Randler R, Kolb DM (1999) Surf Sci 443:19-30

65. Schindler W, Hugelmann P, Hugelmann M, Kärtner FX (2002) J Electroanal Chem 522:49-57

66. Grujicic D, Pesic B (2006) Electrochim Acta 51:2678-2690

67. Lu G, Zangari G (2006) Electrochim Acta 51:2531-2538

68. Huang L, Lee E-S, Kim K-B (2005) Colloids Surf A 262:125-131 
Table 1. Critical nucleus size, $n^{*}$, calculated in electrocrystallization from both the classical and the atomistic models. Supersaturation expressed as potential or overpotential in V, except for D) and E) where the values between ( ) are expressed as $S=a / a_{\mathrm{sat}}=\mathrm{IAP} / K_{\mathrm{SP}}$; ${ }^{\text {a }}$ values reported in the original paper.

\begin{tabular}{lllll}
\hline System & Supersat. & $n^{*}$ clas. & $n^{*}$ atom. & reference \\
\hline A) Ag on C & $\eta=0.09-0.24$ & $3-1^{\mathrm{a}}$ & & 28 \\
& $\eta=0.09-0.16$ & & $1^{\mathrm{a}}$ & \\
& $\eta=0.16-0.24$ & & $0^{\mathrm{a}}$ & \\
& $\eta=0.022-0.038$ & $5-1$ & & 29 \\
B) Cd on $\mathrm{Pt}$ & $\eta=0.071-0.082$ & $3-2^{\mathrm{a}}$ & $3-2^{\mathrm{a}}$ & 30 \\
C) $\mathrm{Cu}$ on $\mathrm{Au}(111)$ & $\eta=0.067-0.117$ & $2-0$ & 1 & 31 \\
D) $\mathrm{PbCl}_{2}$ on $\mathrm{Hg} / \mathrm{Pb}$ & $(190-6720)$ & & \\
& $\eta=0.025-0.100$ & $2-0$ & & 31 \\
E) $\mathrm{PbSO}_{4}$ on $\mathrm{Hg} / \mathrm{Pb}$ & $(7-2450)$ & & \\
& $\eta=0.025-0.060$ & & \\
& $(7-110)$ & & \\
& $\eta=0.060-0.100$ & & & \\
& $(110-2450)$ & & & \\
&
\end{tabular}


Table 2. Critical nucleus size, $n^{*}$, calculated in electrocrystallization from the atomistic model. Supersaturation expressed as potential or overpotential in $\mathrm{V} ;{ }^{\mathrm{a}}$ values reported in the original paper.

\begin{tabular}{|c|c|c|c|}
\hline System & Supersat. & $n^{*}$ atom. & reference \\
\hline A) $\mathrm{Ag}$ on $\mathrm{Si}$ & $-E=0.8-0.9$ & $1-0^{\mathrm{a}}$ & 32 \\
\hline Ag on $\mathrm{C}$ & $-E=0.7-0.9$ & $1-0^{\mathrm{a}}$ & \\
\hline B) Ag on C & $\eta=0.110-0.120$ & 2 & 33 \\
\hline C) AgO on Ag & $E=0.63-0.74$ & 1 & 34 \\
\hline D) $\mathrm{Bi}$ on $\mathrm{C}$ & $-E=0.1-0.35$ & $0^{\mathrm{a}}$ & 35 \\
\hline E) Cd on Cd(0001) & $\eta=0.015-0.045$ & $5^{\mathrm{a}}$ & 36 \\
\hline \multirow[t]{2}{*}{ F) Cd on $\mathrm{Si}(111)$} & $\eta=0.015-0.021$ & 6 & 37 \\
\hline & $0.474-0.520$ & $1-0$ & \\
\hline G) Co on C & $-E=1.2-1.5$ & 0 & 38 \\
\hline H) Co on C & $-E=0.83-0.88$ & $1-0$ & 39 \\
\hline I) Co on C & -E:1.22-1.27 & $0^{\mathrm{a}}$ & 40 \\
\hline J) $\mathrm{Cu}$ on $\mathrm{n}-\mathrm{Si} / \mathrm{TiN}$ & $-E=0.05-0.25$ & $1-0$ & 41 \\
\hline K) $\mathrm{Cu}$ on $\mathrm{Pt}$ & $\eta=0.022-0.032$ & $11^{\mathrm{a}}$ & 42 \\
\hline $\mathrm{Cu}$ on $\mathrm{W}$ & $\eta=0.040-0.055$ & $4^{\mathrm{a}}$ & \\
\hline \multirow[t]{3}{*}{ L) $\mathrm{Cu}$ on Pd } & $\eta=0.040-0.054$ & $4^{\mathrm{a}}$ & 43 \\
\hline & $\eta=0.054-0.082$ & $1^{\mathrm{a}}$ & \\
\hline & $\eta=0.082-0.200$ & $0^{\mathrm{a}}$ & \\
\hline M) $\mathrm{Cu}$ on n-GaAs & $-E=0.49-0.56$ & $0-1^{\mathrm{a}}$ & 44 \\
\hline N) $\mathrm{Cu}$ on n-GaAs & $-E=0.6-0.9$ & $0^{\mathrm{a}}$ & 45 \\
\hline O) $\mathrm{Cu}$ on $\mathrm{C}$ & $E=-0.18-0.10$ & $0^{\mathrm{a}}$ & 46 \\
\hline \multirow[t]{2}{*}{ P) $\mathrm{Cu}$ on $\mathrm{C}$} & $\eta=0.060-0.074$ & $3^{\mathrm{a}}$ & 47 \\
\hline & $\eta=0.074-0.124$ & $1^{\mathrm{a}}$ & \\
\hline Q) $\mathrm{Cu}$ on $\mathrm{Si}(111)$ & $-E=0.50-0.75$ & $0-1$ & 48 \\
\hline \multirow[t]{2}{*}{ R) $\mathrm{Hg}$ on $\mathrm{Pt}$} & $\eta=0.084-0.094$ & 10 & 49 \\
\hline & $0.094-0.106$ & 6 & \\
\hline S) $\mathrm{Hg}$ on Pt & $\eta=0.083-0.093$ & $5^{\mathrm{a}}$ & 50 \\
\hline T) Ni on $\mathrm{C}$ & $-E=0.93-0.98$ & $1-0$ & 39 \\
\hline $\mathrm{U}) \mathrm{Pb}$ on $\mathrm{Ag}(111)$ & $\eta=0.013-0.019$ & $11^{\mathrm{a}}$ & 51 \\
\hline $\mathrm{Pb}$ on $\mathrm{Ag}(100)$ & & $13^{\mathrm{a}}$ & \\
\hline V) $\mathrm{Pb}$ on n-Si(111) & $\eta=0.006-0.010$ & $11^{\mathrm{a}}$ & 52 \\
\hline $\mathrm{Pb}$ on HOPG(0001) & $\eta=0.004-0.007$ & 11 & \\
\hline W) Pt on W & $-E=0.54-0.76$ & $0^{\mathrm{a}}$ & 53 \\
\hline $\mathrm{X})$ Pt on $\mathrm{Ti}$ & $-E=0.56-0.68$ & $0^{\mathrm{a}}$ & 54 \\
\hline Y) $\mathrm{Rh}$ on $\mathrm{Au}$ & $E=0.2-0$ & $1-0^{\mathrm{a}}$ & 55 \\
\hline Z) Rh on PG & $-E=0.17-0.30$ & $0^{\mathrm{a}}$ & 56 \\
\hline a) Sn on C & $\eta=0.160-0.410$ & $1-0$ & 57 \\
\hline b) $\mathrm{Tl}$ on $\mathrm{Si}(111)$ & $\eta=0.003-0.007$ & $18^{\mathrm{a}}$ & 37 \\
\hline c) Zn on C & $-E=1.35-1.70$ & $1-0$ & 58 \\
\hline d) Zn on HOPG & $\eta=0.22-0.37$ & $1^{\mathrm{a}}$ & 59 \\
\hline
\end{tabular}


Table 3. Values of $\Phi\left(n_{1}{ }^{*}\right)-\Phi\left(n_{2}{ }^{*}\right), \Phi(1)$ and $\Delta G(1)$ for some systems. $\eta$ is the overpotential at the point of change of $n^{*}$, expressed in $\mathrm{V}$.

\begin{tabular}{lccccc}
\hline System & $\Phi\left(n_{1}{ }^{*}\right)-\Phi\left(n_{2}{ }^{*}\right) 10^{20} / \mathrm{J}$ & $\Phi(1) 10^{20} / \mathrm{J}$ & $\Delta G(1) 10^{20} / \mathrm{J}$ & $\eta / \mathrm{V}$ & ref. Table n \\
\hline A) Ag on C & $\Phi(1)-\Phi(0)=2.6$ & 2.6 & $1.1-0$ & 0.160 & A Table 1 \\
B) Ag on Pt & $\Phi(1)-\Phi(0)=3.8$ & 3.8 & $0.6-0$ & 0.240 & 17 \\
C) Cu on C & $\Phi(3)-\Phi(1)=4.7$ & & & 0.074 & P Table 2 \\
D) Cu on Pd & $\Phi(4)-\Phi(1)=5.2$ & & & 0.054 & L Table 2 \\
& $\Phi(1)-\Phi(0)=2.6$ & 2.6 & $0.9-0$ & 0.082 & \\
E) Hg on C & $\Phi(1)-\Phi(0)=7.7$ & 7.7 & $0.7-0$ & 0.242 & 17 \\
F) Hg on Pt & $\Phi(10)-\Phi(6)=6.0$ & & & 0.094 & R Table 2 \\
G) $\mathrm{PbSO}_{4}$ on $\mathrm{Hg} / \mathrm{Pb}$ & $\Phi(1)-\Phi(0)=1.9$ & 1.9 & $1.1-0$ & 0.060 & E Table 1 \\
\hline
\end{tabular}

